\title{
Efficiency of Health Saving Method of Young Hockey Players' Training
}

\author{
Zavitayev S.P. \\ Ekaterinburg Insitute of Physical Culture(branch of Ural \\ State University of Physical Culture), \\ Ekaterinburg, Russia \\ yprof@yandex.ru \\ Denisenko Yu. P \\ Naberezhnye State Padagogical University, \\ Naberezhnye Chelny, Russia \\ yprof@yandex.ru
}

\author{
Gumerov R. A. \\ Naberezhnye State Padagogical University, \\ Naberezhnye Chelny, Russia \\ yprof@yandex.ru \\ Denisenko D.Yu \\ Povolzhskiy academy of physical culture, sport and \\ tourism, Kazan, Russia \\ yprof@yandex.ru
}

\begin{abstract}
Research of disease rate among athletes bear witness that during last years the first place as in all over the world take cardio-vascular system , the second - supportingmotor apparatus, the third - respiratory organs, e.g. discases the most sagnificant and are more frequent of hockey players. Muscle loads which rise because of increase of general level of fitness of athletes and increse in growth of skills by means of amount of training loads promote the exhaustion of athletes that in its turn doesnlt lead to healthy development of athletes' organism. Nature of injuries is direct correlation from level qualification of athletes, loads forcing, number of competitions. Reasonsof injuries, circumstances and conditions in which they happen depend on differenr factors both external and internal.

Not uncommon external reasons causing certain changes in organism create internal cause. leading to injury. At present time in hockey trainings aimed at achieving high results on competitions put organism almost on edge of human capacity. That's why it's necessary to search for new means of athletes's
\end{abstract} state normal functioning recovery.

Keywords-health saving methods; sport fitness; means of recovery; athletes; young hockey players.

\section{INTRODUCTION}

Sports activities make sportsman's organism various and reguires very high demands. This great variety of demands match the same variety of circumstanses in which sport actyivity goes on. One of the first and main tasks that should be solved in sport school is preservation of young athletes's health in the process of sports training, competative activity and so on. $[2,3,4]$.

Observing the oppportunities of young athletes sport results increasing without hurting their health, its worth noting that in the practice of system of training there are large reserves enough, revealing and activisation of which may promote extention of negative tendencies that occure so often in sportsme's health that take place in systems and mehtods of sport training[1, 9-13].

However, as analysis of health state of young athletes show such measures don't secure enough sufficiency while using them in practice of sport training. However in the system of sport training there are considerable reserves that can be used in the purpuse of young athletes's health preservation without decreasing quality and final result of training. Necessary loads are not always properly adopted by the organism however by all means certain influence is made on sportsman's health.If the volume of corresponding loads increase the capacities of the organism conditioned by agerelated or individual picularities that threatens with the development of exhaustion, including chronic. That is why in order to save the health it's necessary to regulate the loads that they couldn't harm the health [5-8].

\section{Research Methodology}

The research is made on the basis of children sport hockey schools. The research included 100 young hockey players aged 13-14 years old., with unbroken record of 7 years lessons.

The research was made in the wings of three successive and correlated stages which secure continuation in planning, getting,,working up, interpretation and presentation of theoretic and experimental material.

We made the project development of sport fitness method in terms of health saving approach.. At the beginning stage of corresponding methoics survey project development of health state and initial level of young hockey players sport fitness in sport schoos.

We kept close watch on tendencies in state of young hocley players health on basis of data obligatory medical testing made in each team twice a year according to authorised test procedures. Corresponding information was esteemated by us as one of indicators of resulting character of applied in practice of sport fitness of health saving measures. The level of sport fitness of young hockey players we esteemated according to technical indicators, according to strategies of a game and also by physical conditions and psychological state. That's why the aim of our research laid on development of method of sport fitness that is based on 
essential correlation between the increasing sports mastery by means of above mentioned units of fitness and safe of young hockey players health.Realisation of projected methodics may be illustrated in the following way.

Inspite of the fact that the essence of such concepts as sport and physical culture in general is identified ith activity promoting the health saving, most often it turns out to be in different way. So, in terms of young hockey players according to thorough medical inspections the quantity of supporting motor-motor apparatus injures varies in 170-180 during a year of educational-training lessons, and the state of cardiovascular system is esteemated benificial only at $30 \%$ of hockey players. (data of ascertaning experimenat)

We performed the implementation of health saving methodics to sport fitness with experienced groups of young hockey players. In control group traing process is performed according to traditional (used before) methodics of young hockey players sport fitness. At finishing the aprobation of health saving methodics of sport fitness samples according to the levels of physical, technical, tactic, psychological readiness and quantitative indicator of supporting-motor apparatus injuries and cardiovascular system disorders concerning reaviling the changes of the ascrertaining experiment results. At the stage of forming experiment it was revealed that true positive changes in quantity of supporting motor apparatus injuries were made and aso in indicators of cardiovascular system comparing to control group of tasted hockey players.

\section{III.RESULTS}

Theoretical willingness to realizing health protection in sport fitness of sport schools pupils is characterized by the direction in fact only to the result. In this case from the point of view of management level criterium is also the result. Under this approach to sport fitness of young athletes there is no chance of keeping health. [5-7].

We revealed the pecularities of cardiovascular system state und undertook quantative and qualitative analysis of young athletes supporting-motor apparatus injuries. Also we defined initial levels of sport fitness in technical, tactical, physical and psychological aspects.It should be noted that each age category of pupils has individually made training time-table of sport fitness in the annual cycle that corresponds work-to-date at training lessons. But the main accent is made on achievement of possible higher sport results by means of accepted standard loads without the emphasis on saving health of athletes using various means of recovery.

Reasons low of sport school activities effectivity from the point of view of health saving of young athletes are because of the athletes sport fitness performing joint health saving methodics absence of that could be realized on each year of education. A lot of trainers confess that in their work they pay not enough attention to the development work and and realization in sport fitness of these or those pedagogical means of performing of health protection having obviously insufficient level of profeccional readiness in these aspects..

The main purpose of our research is creating preconditions so that trainers-teachers had the opportunity take measures health protecting of athletes in sport schools through securing parity rate between sports mastery and saving health of pupils.

Health saving method sport fitness worked out by us allows us to project and realize training process with the focus on solving this problem in intimate identity of its components. The basis for making health saving methodics of sport fitness make reserves of health protection of young hockey players. As such step forward normalization of coorelation between physical, technical, tactical and psychological fitness, rasing the profile of safty implementation Methodics of sport fitness sugested by us observed in parity rate between development of sport fitness and health protection of athletes based on the concept of health protection.. Its main principles are built on the fact that training process is worth building with the direction of health protection aiming to creating further perspective tendencies to the growth of sport results by means of high readiness of the organism to accept loads which lead to progressing growth of mastery and keeping the health of athletes. On the basis of worked out methodics of sports fitness reserves of project of content of fitness are defined for realization healthsaving training process. Realisation of methodics carried out in the wings of experiment work. Realizatiom of healthsaving metodics that was carried out in the wings of experimental work aimed at securing parity rate between development of sport fitness and health saving of young athletes showed the opportunities of using xorresponding theoretical evidences in the practice of sport fitness. Implementing on its basis healthsaving methodics of sport fitness actuated decrease of injuries of supporting motor apparatus and disorder of cardiovascular system of young athletes.. Their realization in the practice of sport fitness was effective enough from the point of view of sport achievements and health protection, parity rate achievement between data indicators, that in general confirmed the truth of our yheoretic conclusions..

As the carried out experiment show there are certain means of sport fitness truly influencing the saving the health of young hockey players. It is certain that physical fitness influence the state of cardiovascular system and this fitness includes general physical endurance, locomotive-coordination capacity and speed endurance, and also tactical and psychological fitness in terms of level of tension that is defined by external emotions, functional responses and psychomotor procecess. It is certain that level of physical fitness influence on getting injuries of supporting-motor apparatus and level of physical fitness includes flexibility, speed-power, speed and locomotive-coordination capacities, tactical fitness and psychilogicac fitness which is expressed in the level of physical tension Implementation of corresponding changes to the mehodology of sport fitness aimed at protecting health in turms of increasing professional skills of young hockey players gave positive changes in the state of cardiovascular system which got better in experemental group at $36,2 \%$ in relation to the control group.There is also the decriesease of supporting-motor apparatus injuries, the difference between experimental and control groups according to this indicator is $41 \%$.

Being worked out and time-tested by us on the basis of stated results of pilot testing methodology of health protection of young athletes in the process of sport fitness makes it 
possible to state that supposing volume destribution of work according to the kinds of sport fitness allows at the same time increase nesessary level of sport mastery and promote preserving and in the other case increasing the health of young hockey player.In the future this by no means will promote the progressive growth of individual mastery, and also team success which is expressed in high sport achievements.

\section{CONCLUSION}

According to analysis of theoretic sources and practical data the state of the problem of saving young athletes's health and not decreasing at that the level of sport fitness expressed in sport achievements at the present time is that for its solving it should be taken various measures including pedagogical. Health saving methodology of sport fitness of young athletes worked out by us which has the parity rate between increasing sport mastery and health protection gives the opportunity to project and realize training proccess with the commitment to solving this problem in intimate identity of its components. Positions erected in the hypothesis in general drew its conformation in the process of carried out experiment. Results resieved can be concluded in the following way:

Catering to the achievements of the highest results it makes sence to put not only on final result but if possible on health promotion of athletes in the process of sport fitness. Distinguishing sport results and healthof young athletes as the leading criteria of efficiency of sport fitness is caused by existing correlations between given directions expressed in their controdictory unity.Specific character of sport fitness is that loads on young athletes that inevitably attend their activity aimed at increasing sport mastery make a very serios factor which can make negative influence on young hockey players' health. At the same time shift of dominate role to the side of activity aimed at health saving of athletes may have affected the level of sport fitness to the achievement of highest results in a negative way.This defines the nesessity of setting the parity rate between corresponding directions of activity. The opportunity of building the methodology of sport fitness is defined that promote formation of health saving direction of training process of young athletes.. The opportunity lies in finding the connection between received disorders made during the training process and kinds of sport fitness constantly used for achieving certain level of sport mastery. This gives the opportunity without going away from target goals and corresponding tasks of sport fitness solve the task of health protection of athletes using corresponding types of fitness that influence the increase of necessary growth of sport fitness in the parity rate with saving health of young athletes.

The basis for building healthsaving methodology of sport fitness make the reserves of health protection of young athletes. As such act normalization of coorelation between physical, technical, tactical and psychological fitness, rising the profile of safety implementation and also adition of used methods of physical and psychical recovery with the help of non-traditional means based on yoga system.. Method of sport fitness suggested by us is observed in the parity rate between development of sport fitness and athletes's health protection is based on health protection concept. Its fundamental principals are based on the fact that cooperation of participants of sport fitness in training process reasonably to built aiming at saving health with the purpose of origin of further, perspective tendencies of growth of sport results because of the high readiness of the organism to accept loads which lead to progressive growth of mastery and also athletes's health protection. On the basis of worked out methodology of sport fitness reserves of project of content of fitness are defined to perform health saving training process..

Realisation of meyhodology of health protection carried out in the wings of experimental work aimed at securing parity rate between development of sport fitness and health saving of young sportsnen showed the opportunities of usage corresponding theoretical evidence in practice of sport fitness.. Implementation of made on its basis healthsaving methodology of sport fitness actuated decrease of injuries of supporting-motor apparatus and disorders of cardiovascular system of young athletes. The realization on practice of sport fitness was effective enough from the point of view of sport achievements and health saving of young athletes, parity rate achievement between given indicators that in general confermed truth of our theoretical conclusions. At the same time there appeared a range of problems that couldn't be solved at the result of the given research and there were no full answers to some questions. There are actual directions referring to sport fitness of athletes of all ages, sport schools etc. Problems of coaching staff training of sport school in the direction of heath saving remsained unresearched.There is afield for additional researches specially dedicated to the descovery of practical aspects of implementation of healthsaving sport fitness. These problems solving didnlt include the aim of our research. However there turned out to be possible approaches to working out of these problem. Our further researces will be dedicated to these problems.

\section{References}

[1] Agadzhanyan N.A. Civillization and health. Stavropol: Book house. 1990, 93.

[2] Peshkov V.F. Actual questions of safety of health doing sport excersises and physical culture: Materials of 6 international scientific conference. Tomsk State Pedagogical University. Tomsk. 2003, 416.

[3] Serikov S.G. Health saving education: parity rate of health and education of students:Monograph. Chelyabinsk: Chelyabinsk State Scientific Educational Center University of Russian Academy of Education. 2002, 226.

[4] Serikov S.G. Security of parity rate of education and health of students in theory and practice of education. Doctor's thesis. Ural State Academy of Physical Culture. Chelyabinsk. 2002, 385.

[5] Ahmetov A.M. et al. Stimulation of conciousness of motivation in physical self-improvement of students. Theory and practice of physical culture. 2019,3 , pp. 28-29

[6] 6.Sevenov S.A. et al. Psychology and education technologies of management of development by socially important qualities of students by means of physical cullture and sport. Theory and practice of physical culture. 2019, 4, pp. 39-40

[7] Lyach V.I., Makeson G.B. Conception of physical education and health of children and teenagers. M . 1992, 234.

[8] Mainberg E. Main problems of pedagogic and sport. M.: AspectPress. 1985,121 . 
[12] Md Al Mamun, Zinaida Kuznetsova. History of drop Roball. The Russian Journal of Physical Education and Sport. 2018, 13(2), pp. 98-107. DOI: 10.14526/02_2018_318.

[9] Markov V.V. Basis of healthy lifestyle and disease privention: Study book. M.: Academy. 2001, 319.

[10] Shedrina A.G. Health and mass physical culture: methodological aspects// Theory and practice of physical culture. 1989, 4, pp. 5-7.

[11]Dave R.H. Lifelong education and school curriculum. Hamburg. 1973, pp. $14-25$. 